\title{
Effect of Metallic Waste Addition on the Physical and Mechanical Properties of Cement-Based Mortars
}

\author{
Jose Norambuena-Contreras ${ }^{1, *}(\mathbb{1})$, Ariel Cartes ${ }^{1}$, Irene Gonzalez-Torre ${ }^{1}$, Manuel Chavez ${ }^{2}$ and \\ Antonios Kanellopoulos ${ }^{3}$ [D \\ 1 LabMAT, Department of Civil and Environmental Engineering, University of Bío-Bío, 4051381Concepción, \\ Chile; aricarte@alumnos.ubiobio.cl (A.C.); irenegon@ubiobio.cl (I.G.-T.) \\ 2 Department of Civil Engineering, University Andres Bello, 4300866 Concepción, Chile; \\ manuel.chavez@unab.cl \\ 3 School of Engineering and Technology, University of Hertfordshire, Hatfield AL10 9AB, UK; \\ ak17acu@herts.ac.uk \\ * Correspondence: jnorambuena@ubiobio.cl; Tel.: +56-41-311-1599
}

Received: 17 April 2018; Accepted: 8 May 2018; Published: 5 June 2018

Featured Application: The development of advance construction materials based on waste valorisation is a reality. The cement-based mortar with recycled metallic waste presented in this study could be potentially used as a building material with crack self-monitoring properties.

\begin{abstract}
This paper investigates the influence of the type and amount of recycled metallic waste on the physical and mechanical properties of cement-based mortars. The physical and mechanical properties of cement mortars, containing four different amounts of metallic waste (ranged 4 to $16 \%$ by cement weight), were evaluated by measuring the bulk density, total porosity, flexural and compressive resistance, and dynamic elastic modulus by ultrasonic tests. All the properties were measured on test specimens under two curing ages: 7 and 28 days. Additionally, the morphological properties and elemental composition of the cement and metallic waste were evaluated by using Scanning Electron Microscopy (SEM), energy dispersive X-ray spectroscopy (EDXS), and X-ray fluorescence (XRF). Main results showed that the addition of metallic waste reduced the bulk density and increased the porosity of the cement-based mortars. Furthermore, it was observed that flexural and compressive strength proportionally increased with the metallic waste addition. Likewise, it was proven that elastic modulus, obtained by compressive and ultrasonic tests, increases with the metallic waste amount. Finally, based on a probability analysis, it was confirmed that the addition of metallic waste did not present a significant effect on the mechanical performance of the cement-based mortars.
\end{abstract}

Keywords: cement mortar; metallic waste; waste influence; physico-mechanical properties

\section{Introduction}

Cement mortars are building materials, typically made from a mixture of fine sand, cement, and water, which are widely used in civil engineering. However, adverse environmental conditions, such as: temperature variations [1], sulphates attack [2], and contact with acids [3], combined with the external loads [4], produce a reduction in their mechanical resistance and durability over time. With the aim of improving their mechanical resistance, different types of reinforcement materials can be added to the mortar [5]. Banthia and Dubeau [6] experimentally proved that the use of carbon and steel fibres increase the adherence ability of the mortar compared with a conventional one. However, Brandt [7] proved that the improvements in the properties of reinforced cement-based materials mainly depend on the morphology and type of the used reinforcements, i.e., particles or fibres. 
The most commonly used particle-shaped reinforcements to improve the mechanical properties of cement-based materials are steel powder, carbon powder, and crushed steel shavings [6-8]. Likewise, organic fibres (palm, cellulose, hemp, etc.) [9], carbon fibres [10], synthetic fibres (e.g., polypropylene, polyethylene, polyvinyl alcohol, etc.) [11], and metallic fibres ([12-17]) are amongst the most used fibre-shaped reinforcements. Nevertheless, over the last few years, the high cost of the commercial fibres has promoted the use of recycled metallic waste $[10,18]$ to develop new cement-based materials that are more resilient [12], environmentally friendly [13], and with advanced properties [18].

In this context, authors like Quadir et al. [8], Martinelli et al. [12], Sengul [13], and Graeff et al. [14] used recycled steel particles and steel fibres from End of Life Tyres (ELTs) with the aim of mechanically reinforcing mortars and concrete. Quadir et al. [8] partially replaced fine aggregates with recycled steel particles in concrete. As the main result, flexural resistance of concrete reinforced with steel particles was 38\% higher than that of a conventional concrete. Additionally, Martinelli et al. [12] studied concrete samples reinforced with two different types of fibres, commercial and recycled steel fibres, in different contents. In this research, they observed that the test samples with higher percentages of recycled fibres presented lower mechanical resistance. Besides, commercial fibres cannot be totally replaced by recycled fibres, due to the significant reduction of their mechanical properties.

Moreover, Sengul [13] demonstrated that recycled steel fibres from ELTs (diameter 0.1-2 mm) could be used to reinforce cement-based materials, although their compressive and flexural properties were lower in comparison with materials reinforced with commercial metallic fibres. Wu et al. [17] highlighted that one of the disadvantages of the addition of fibres in cement-based materials is the reduction of their workability, which can affect the microstructure and physical properties of cement-based materials. In this context, Lee and Jacobsen [19] evaluated the microstructure of mortars with steel fibres using Scanning Electron Microscopy, concluding that the porosity present in the interface matrix-fibre increases the total porosity of the mortar. Therefore, this increase of the total porosity can cause a decrease in the mechanical properties of the mortars. Nevertheless, this negative effect can be variable depending on the amount of metallic fibres added to the mortar matrix and on the type of mechanical test used to evaluate the effect of fibres [20].

Recently there has been a lot of interest in the development of innovative cement-based materials with crack self-sensing capabilities [21,22] or general self-sensing properties $[23,24]$. These materials are based on the addition of electrically conductive fibres or particles to the cement matrix and the modification of its electrical properties, without compromising the mechanical performance of the composite material. In this context, Lataste et al. [25] concluded that the variation of the electrical properties of cementitious materials reinforced with metallic fibres depends on the amount and morphology of the added fibres and also on their physico-mechanical properties, moisture content, and their distribution and connectivity inside the material.

The existing literature has identified some effects of the metallic waste on cement mortars. Nonetheless, there are still many open research questions that need to be addressed in order to understand the associated phenomena. For example, the interaction between the cementitious matrices and the waste metallic inclusions is not yet clear. Another less researched area concerns the optimum amounts and types of metallic waste to yield cement-based composites with adequate properties. Therefore, the main objective of this paper is to evaluate the influence of the type and amount of metallic waste on the physical and mechanical properties of cement mortars designed with self-monitoring purposes. Additionally, this paper corresponds to a second part of the work recently published by Norambuena-Contreras et al. [18] related to the measurement of the electrical and thermal properties of cement-based mortars containing recycled metallic waste. 


\section{Materials and Methods}

\subsection{Raw Materials}

The raw materials used for the manufacturing of mortars were: Portland-Pozzolana Cement type IP [26] with density $3.09 \mathrm{~g} / \mathrm{cm}^{3}$, fine sand (particle size between 0.15 and $2.0 \mathrm{~mm}$ ) with particle density $2.81 \mathrm{~g} / \mathrm{cm}^{3}$, and a polymer synthetic-based superplasticiser with density $1.08 \mathrm{~g} / \mathrm{cm}^{3}$. In addition, two different types of recycled metallic waste were mechanically cut in different sizes and added to the cement mortar matrix: steel wool fibres, Figure 1a, and steel shavings, Figure $1 \mathrm{~b}$.

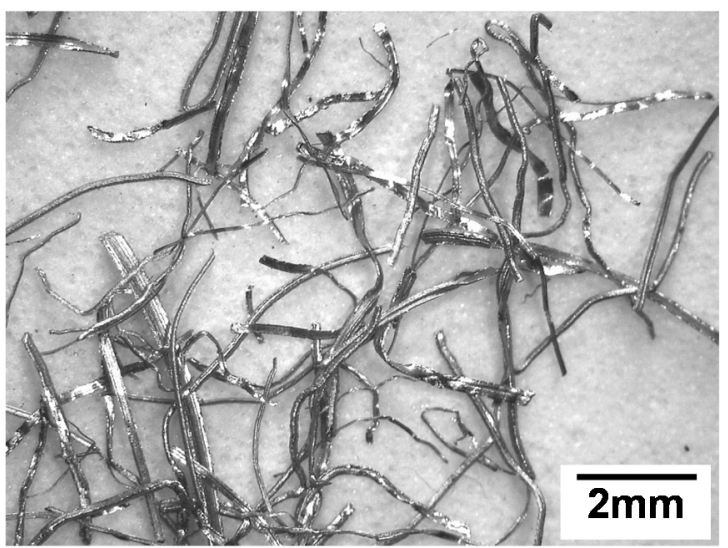

(a)

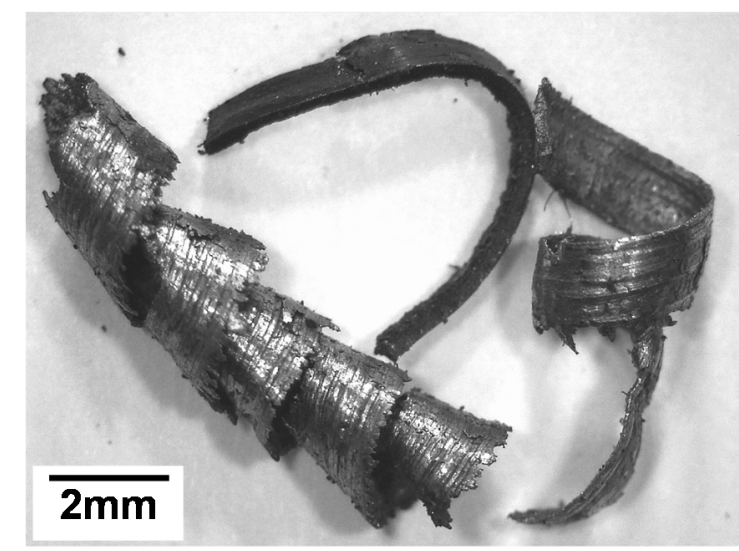

(b)

Figure 1. Optical images of recycled metallic waste: (a) steel wool fibres; and (b) steel shavings.

\subsection{Manufacturing of the Test Specimens}

Table 1 shows the proportions in weight and volume of the raw materials used. A water/cement ratio by weight of 0.5 was set for all the mortar mixtures with the aim of obtaining a normal consistency according to EN 196-3:2005+A1:2009 [27]. Nine different types of cement mortars with the same water/cement ratio but with four different metallic waste amounts from $4 \%$ to $16 \%$ by cement weight were manufactured. Raw materials were mixed in a standard laboratory planetary mixer, adding the materials in the following order: first the cement and fine sand, second the water with the additive, and finally the metallic waste, when applicable. The mixing and manufacturing methodologies of the cement-mortar specimens were as follows:

- First, cement and sand were mixed under dry conditions for $60 \mathrm{~s}$ at low speed. At the same time, water and additive were manually mixed in a separate bowl. Then, water with additive was added to the laboratory mixer slowly for $60 \mathrm{~s}$, and then quickly for $60 \mathrm{~s}$.

- After that, the mix was left for $120 \mathrm{~s}$, and then the process was finished with $60 \mathrm{~s}$ of fast mixing. In cases where metallic wastes was added to the mortar, they were gradually incorporated while mixing at low speed in order to avoid clusters. Then, the reinforced mortar mixture was mixed at low speed for $120 \mathrm{~s}$.

- After the mixing process, the cement-mortar mixtures with and without metallic waste were poured into the prismatic metallic moulds $(40 \times 40 \times 160 \mathrm{~mm})$ from one end of the specimen to the other end using a wide scoop. The specimens were slightly vibrated for $5 \mathrm{~s}$ to minimise the presence of air bubbles inside them.

- Following the casting and compaction procedures, the prismatic moulds were covered with acetate sheets and placed in the laboratory at ambient conditions for $24 \mathrm{~h}$ to set prior to demoulding.

- After demoulding, the specimens were cured in a water tank with a standard controlled atmosphere at a temperature of $22 \pm 5{ }^{\circ} \mathrm{C}$ and $97 \pm 2 \%$ humidity for 7 and 28 days. 
Table 1. Proportions in weight and volume of the raw materials used in the cement-based mortars.

\begin{tabular}{cccccc}
\hline $\begin{array}{c}\text { Cement } \\
\text { Weight (g) }\end{array}$ & $\begin{array}{c}\text { Sand Weight } \\
(\mathbf{g})\end{array}$ & $\begin{array}{c}\text { Water Weight } \\
\mathbf{( g )}\end{array}$ & $\begin{array}{c}\text { Additive Volume } \\
\left.\mathbf{( c m}^{\mathbf{3}}\right)\end{array}$ & $\begin{array}{c}\text { Fibres and } \\
\text { Shavings Amount } \\
(\% \text { by Weight/Cement) }\end{array}$ & $\begin{array}{c}\text { Weight of Fibres } \\
\text { and Shavings (g) }\end{array}$ \\
\hline & & & 4 & 18 \\
450 & \multirow{2}{*}{1350} & 225 & 4.2 & 12 & 36 \\
& & & & 16 & 54 \\
\hline
\end{tabular}

Finally, a total of 216 prismatic test specimens were manufactured, see Figure 2a. A total of 192 specimens contained fibres and shavings, while 24 reference specimens did not incorporate any metallic waste.

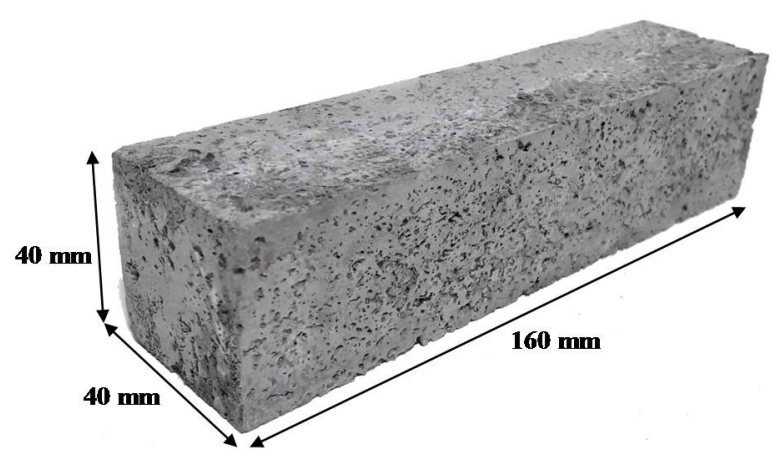

(a)

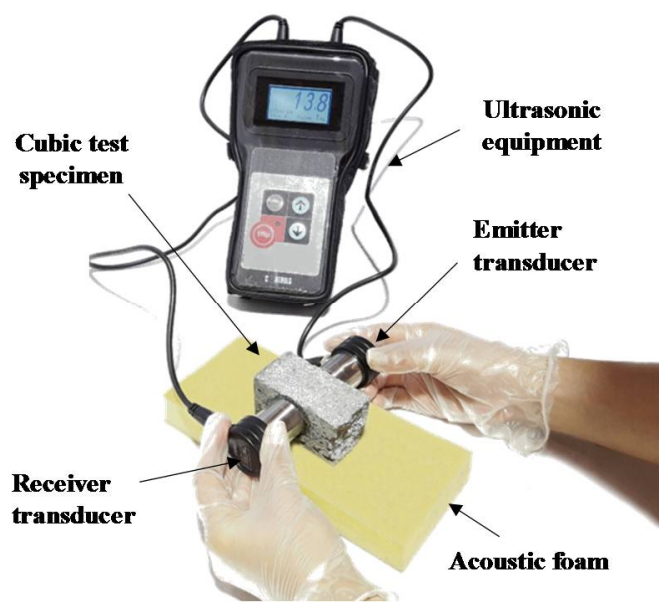

(b)

Figure 2. (a) Mortar specimen and (b) elastic dynamic modulus of cement mortars by ultrasonic test.

\subsection{Chemical Characterisation of Raw Materials}

The raw materials used for the manufacturing of the cement mortars were chemically characterised by elemental microanalysis and oxide content by using energy dispersive X-ray spectroscopy (EDXS) and X-ray fluorescence (XRF). Basic element contents were measured in the metallic waste (fibres and shavings) by EDXS characterisation, using a Scanning Electron Microscope TESCAN Vega-3 LMU with an energy dispersive X-ray microanalysis unit incorporated. Additionally, oxide contents were measured in the cement and sand by XRF characterisation, using an ARL Advant XP X-ray fluorescence spectrometer equipped with proportional flow and scintillation detectors. The chemical compositions of the cement and sand are shown in Table 2.

Table 2. Oxide chemical composition measured by X-ray fluorescence (XRF) for the Portland-Pozzolana cement and fine sand used in the study. The uncertainty associated with the measurements was less than $1 \%$ [18].

\begin{tabular}{ccccccccccc}
\hline Oxide Type/Amount (wt \%) & $\mathrm{SiO}_{2}$ & $\mathbf{A l}_{2} \mathbf{O}_{3}$ & $\mathrm{Fe}_{2} \mathbf{O}_{3}$ & $\mathbf{M g O}$ & $\mathbf{C a O}$ & $\mathbf{N a}_{2} \mathbf{O}$ & $\mathbf{K}_{\mathbf{2}} \mathbf{O}$ & $\mathbf{S O}_{3}$ & $\mathrm{TiO}_{2}$ & $\mathbf{S u m}$ \\
\hline Portland-Pozzolana Cement & 25.95 & 14.41 & 5.39 & 2.76 & 40.56 & 2.45 & 1.34 & 2.31 & 0.53 & 95.69 \\
Fine Sand & 44.93 & 20.81 & 7.83 & 6.13 & 9.09 & 4.94 & 0.68 & - & 1.87 & 96.29 \\
\hline
\end{tabular}

\subsection{Morphological Characterisation of Metallic Waste}

To determine the morphological characteristics of the metallic waste added to the cement mortars, approximately 120 fibres and shavings were randomly selected from all the waste stored for the manufacturing. The length and diameter of the fibres and the length and width of the shavings were 
determined by taking photographs under an optical microscope Leica EZ4 with 35x magnification, and each morphological value was calculated by using the software Image $J^{\circledR}$. Finally, the surface aspect and cross-section of the metallic waste were analysed by SEM images obtained using a Scanning Electron Microscope, TESCAN Vega-3 LMU.

\subsection{Fractographic Analysis of Cement Mortar Failure Surfaces by SEM}

With the aim of assessing the flexural failure surfaces and characterising the interface bonding between metallic waste and cement composite matrix, a fractographic evaluation was conducted on selected reinforced cement-mortar failure surfaces by using Scanning Electron Microscope images.

\subsection{Measurement of the Density of Metallic Waste}

The density of the dry metallic waste was measured by using Gas Pycnometer AccuPyc II 1340 equipment based on the gas displacement method. The sample weight of the metallic waste in each test was about $15 \mathrm{~g}$. For all tests, the inert gas, used as the displacement medium into the fibres or shavings, was helium.

\subsection{Physical Characterisation of the Test Specimens}

To evaluate the effect of the type and content of recycled metallic waste on the physical properties of the cement mortars after 7 and 28 days, bulk density $(\rho)$ and water accessible porosity $(n)$ of each test specimen with and without metallic waste were measured and determined according to the ASTM C642 Standard [28]. Then, the representative values of density and porosity of each cement mortar mixture were calculated as the average value of 12 specimens without metallic waste and 24 specimens with metallic waste for each curing age.

\subsection{Flexural and Compressive Properties of the Test Specimens}

To evaluate the influence of the type and amount of metallic waste on the mechanical properties of the cement mortars after 7 and 28 days, flexural and compressive strength of all prismatic test specimens with and without metallic waste were measured using mechanical tests. Flexural and compressive strength of each mortar mixture were assessed in accordance with the ASTM C348 [29] and ASTM C349 [30] Standards, respectively. Flexural strength was determined as the average of 12 prismatic test specimens for each mortar mixture and curing age. In contrast, compressive strength was determined as the average of 24 cubic specimens obtained after the flexural test (two pieces were obtained from each flexural prismatic specimen) for each mortar mixture and curing age. Finally, the static elastic modulus $\left(E_{c}\right)$ of the cement mortars after 7 and 28 days was also calculated from the compressive curve results.

\subsection{Dynamic Elastic Modulus Measurement by Ultrasonic Test}

To evaluate the influence of the metallic waste on the dynamic elastic modulus of the cement mortars after 7 and 28 days, the dynamic elastic modulus of all prismatic test specimens with and without metallic waste was measured by using ultrasonic pulse velocity tests in accordance with the ASTM C597 Standard [31]. Dynamic measurements of ultrasonic tests were made using the propagation of compressional waves (P-waves) through the cubic specimens obtained from the prismatic specimens after the flexural test. Ultrasonic measurements were carried out before the compressive strength tests described in Section 2.8. To do this, an ultrasonic equipment model 58-E4800 UPV (Controls Group) with two piezoelectric transducers of $54 \mathrm{kHz}$ was used, see Figure $2 \mathrm{~b}$.

Additionally, couplant was used to ensure a good contact between the transducers and the test specimen faces. To perform the tests, each specimen was placed on an acoustic foam support and measured across its thickness, see Figure $2 b$. Thus, the equipment determined the ultrasonic pulse propagation time for each test specimen, measured in microseconds, and it was used to determine the 
P-wave velocity $\left(V_{p}\right)$ of each mortar specimen, knowing its thickness. The representative value of the ultrasonic time on each test specimen was calculated as the average of three repetitions. Therefore, the dynamic elastic modulus $\left(E_{u}\right)$ of each specimen was calculated from the measured P-wave velocity according to Equation (1):

$$
E_{u}=\frac{(1+v)(1-2 v)}{(1-v)} \rho V_{p}^{2}
$$

where $v$ and $\rho$ are the Poisson's ratio and bulk density $\left(\right.$ in $\mathrm{g} / \mathrm{cm}^{3}$ ) of the test specimen, respectively. In this study, the Poisson's ratio value of all cement mortar specimens with and without metallic waste was considered equal to 0.20 , according to Valentini et al. [32]. Finally, the representative value of the dynamic elastic modulus $\left(E_{u}\right)$, measured in $\mathrm{MPa}$, was determined as the average of the 24 cubic specimens for each mortar mixture and curing age.

\section{Results and Discussion}

\subsection{Analysis of the Morphology and Composition of Metallic Waste}

Figure 3 shows the morphological properties of steel shavings and steel wool fibres before the mixing process, adjusted to a Weibull probability distribution function, see Figure $3 \mathrm{a}, \mathrm{b}$, respectively. The Weibull probability distribution function has been used in this study as a damage function on the metallic waste [10], considering that, due to the cutting action of recycled metallic waste, many small cuts occur during each specific industrial process, such as longitudinal cuts for fibres and turning cuts for shavings. From these Figures, a good data fitting is observed due to the fact that all the morphological parameters, regardless of the waste type, can be aligned in a 1:1 straight line. This result was similarly reported in previous studies about the morphological characterisation of recycled metallic fibres added to rubber [33] and asphalt [34] composite materials.

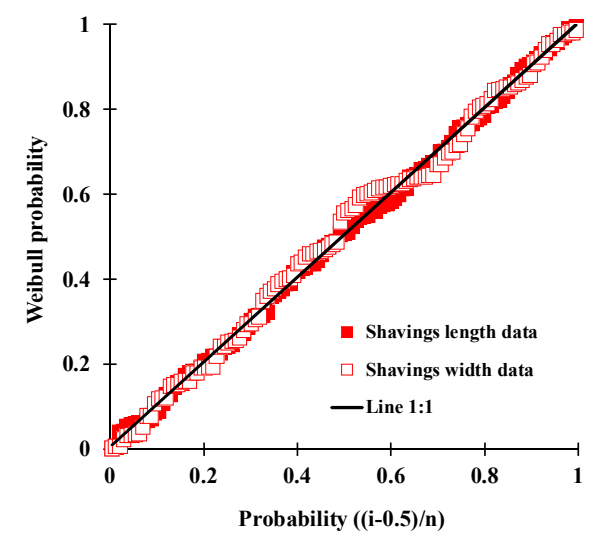

(a)

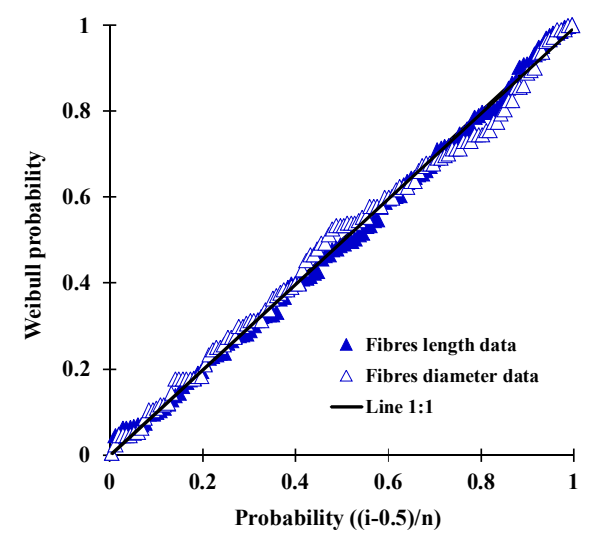

(b)

Figure 3. Weibull probability-probability plot of the (a) length and width of the metallic shavings and (b) length and diameter of metallic fibres.

Moreover, Table 3 presents the results of statistical parameters obtained for the morphological data measured on the 120 shavings and fibres. In this Table, it was proven that the steel shavings (average length $7.181 \mathrm{~mm}$ ) are on average longer than the steel wool fibres (average length $5.833 \mathrm{~mm}$ ). Likewise, it was confirmed that the shavings' width (average $1.31 \mathrm{~mm}$ ) is 10 times greater than the fibres' diameter (Table 3). As a result, the shavings ranged from 3 to $21 \mathrm{~mm}$ length, while the fibres ranged from 2 to $14 \mathrm{~mm}$ length. Regarding their morphology, the added fibres can be considered as medium-length fibres [33]. In addition, the diameter calculated from the measurement of individual fibres by optical microscope was on average $0.133 \mathrm{~mm}$, so they can be considered as a thick type of fibre [35]. More information on the morphology of the recycled shavings used in this study can be 
found in the work recently published by Norambuena-Contreras et al. [18]. In this study, a classification by typology of the recycled shavings has been developed by using optical microscopy.

Table 4 shows the basic elemental composition results obtained by EDXS for the metallic waste used in the study. Based on the results, it was proven that steel wool fibres were composed of low-carbon steel, with a bulk density of $7.16 \mathrm{~g} / \mathrm{cm}^{3}$. Likewise, steel shavings were formed of ferritic stainless steel, with a bulk density of $7.95 \mathrm{~g} / \mathrm{cm}^{3}$. These results proved that steel shavings are more brittle and dense than steel wool fibres and, therefore, more susceptible to breakage during the mixing process. This became evident on a few occasions by observing SEM images of shavings and fibres after mixing (Figure 4). Steel shavings appeared to suffer damage as a result of mechanical cleavage during mixing (Figure 4a). In this case, fracture and dislocation of various layers of the steel shavings were apparent. In contrast, steel wool fibres made of low-carbon steel and with an average aspect ratio of 44 were more ductile than shavings. Thus, they did not seem to suffer any damage as a result of mixing. Nonetheless, they were more susceptible to the formation of clusters and aggregations during the mixing process (Figure $4 b$ ).

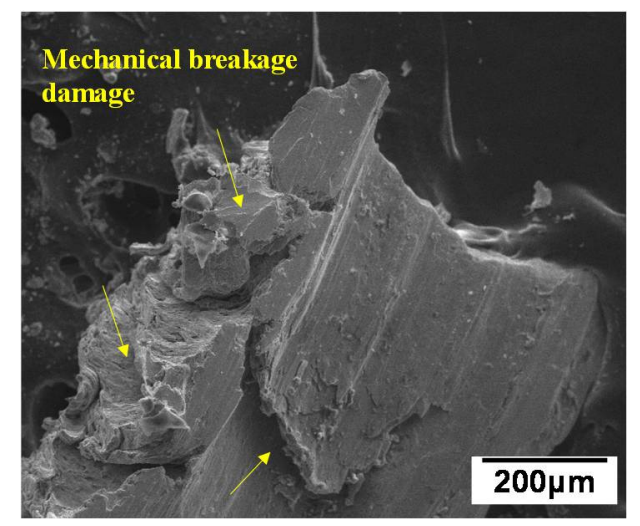

(a)

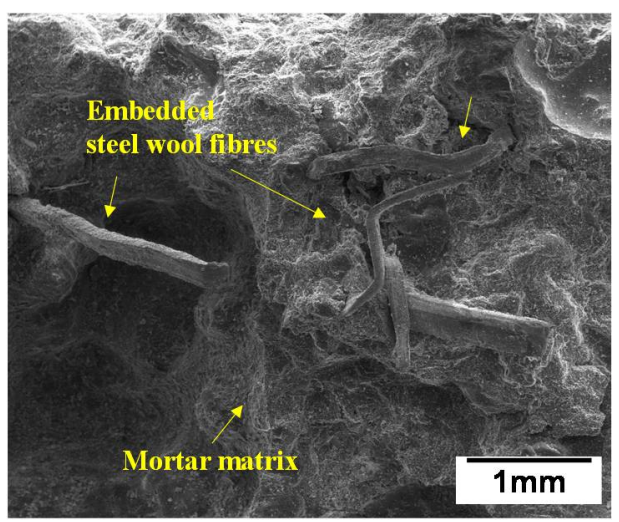

(b)

Figure 4. SEM images of (a) individual steel shaving after mixing process and (b) ductile steel wool fibres embedded in cement matrix.

Table 3. Statistical parameters for all the morphological data measured in shavings and fibres.

\begin{tabular}{ccccc}
\hline \multirow{2}{*}{ Statistical Parameters } & \multicolumn{2}{c}{ Shavings } & \multicolumn{2}{c}{ Fibres } \\
\cline { 2 - 5 } & Length & Width & Length & Diameter \\
\hline Average (mm) & 7.181 & 1.310 & 5.833 & 0.133 \\
Variance (mm $\left.{ }^{2}\right)$ & 11.344 & 0.769 & 3.948 & 0.003 \\
Std. Dev (mm) & 3.368 & 0.877 & 1.987 & 0.056 \\
CV (-) & 0.469 & 0.669 & 0.341 & 0.422 \\
Range (mm) & $3-21$ & $0.5-4$ & $2-14$ & $0.1-0.5$ \\
$\mathrm{~N}^{\circ}$ samples (unit) & 120 & 120 & 120 & 120 \\
\hline
\end{tabular}

Table 4. Elemental analysis measured by X-ray spectroscopy (EDXS) for the recycled metallic waste used in the study [18].

\begin{tabular}{ccccccc}
\hline \multirow{2}{*}{ Metallic Waste } & \multicolumn{6}{c}{ Element Type and Amount (wt \%) } \\
\cline { 2 - 7 } & Fe & Mn & Si & Cr & C & Sum \\
\hline Shavings & 97.49 & 1.44 & 0.51 & 0.21 & 0.30 & 99.95 \\
Fibres & 98.38 & 1.30 & 0.18 & - & 0.12 & 99.98 \\
\hline
\end{tabular}




\subsection{Effect of Metallic Waste on the Mechanical Strength of the Test Specimens}

Figure 5 shows the average results of the flexural (Figure 5a) and compressive (Figure 5b) tests. It can be observed in Figure 5 that the addition of shavings increased the average values of flexural strength compared with reference mortars, while the addition of fibres caused slight variations of this property, reducing and increasing average flexural strength at 7 and 28 days, respectively. Moreover, compressive strength was increased at 7 days, both with fibres and with shavings. In contrast, at 28 days, the addition of metallic waste did not improve the compressive strength of specimens. In summary, (i) overall, the mechanical resistance of mortar specimens with metallic waste proportionally increased with the increase of the waste content and (ii) test specimens with shavings presented higher average values than specimens with fibres, both in the case of flexural and compressive strength. This difference in the obtained results was attributed to the morphology and elemental composition of the metallic waste added to the mortar that presented a different mechanical behaviour depending on their distribution inside the specimens [18]. Thus, depending on the position and orientation of the metallic waste inside the specimens, they can contribute in greater or lesser degree to the reduction in mortar specimen cracking due to the flexural or compressive efforts. To better illustrate this, Figure 6 shows a schematic representation of the theoretical cracking process produced during the flexural and compressive tests on cement-mortar specimens with shavings and steel wool fibres, respectively. In this illustration, it can be observed that metallic waste particles experienced shear and tensile efforts during the flexural and compressive tests, which mainly depended on the orientation of the waste and on their morphological properties, such as the surface morphology and aspect ratio.

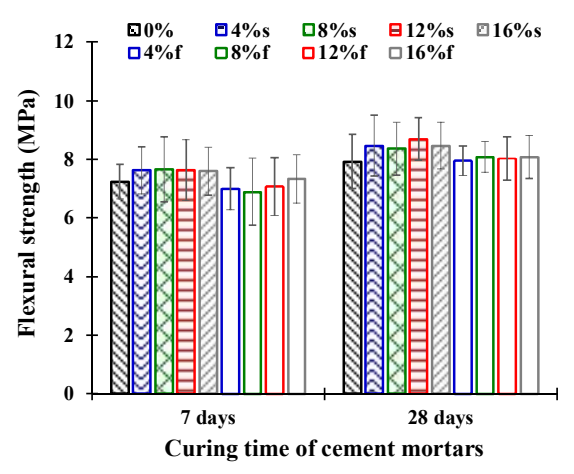

(a)

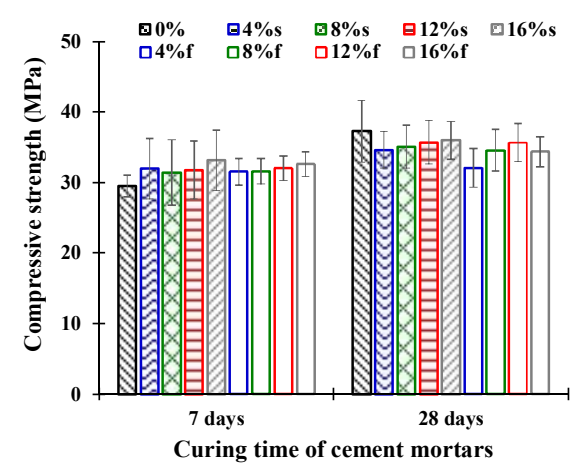

(b)

Figure 5. Average results of mechanical strength: (a) flexural and (b) compressive strength of the mortar specimens with different waste type, content, and curing times (s: shavings; f: steel wool fibres).

Additionally, SEM images shown in Figure 7 confirmed that the metallic shavings have a rougher surface compared with the fibres which presented a smooth surface. The default geometrical characteristics of steel shavings provided a larger surface area on which the hydration products could proliferate. Indeed, this is what Figure 7a verifies. The rough surface of the steel shavings facilitated the adherence between the reinforcement material and the mortar matrix, thus allowing more hydration products to bond onto the shavings surface. This bonding ability between shavings and mortar increased their mechanical interlock and subsequently the probability of shavings failing under shear when they were submitted to tensile loading, consequently avoiding slipping on the shavings' edges (Figure 6a). In contrast, due to the high average aspect ratio of metallic fibres and to their smooth surface, see Figure $7 \mathrm{~b}$, they were more susceptible to failure by pull-out slipping, before reaching their shear strength (Figure $6 \mathrm{~b}$ ). This behaviour was mainly due to the smooth surface of the fibres that reduced the adherence between fibres and the mortar matrix, thus facilitating the slipping of the 
fibres (Figure 7b). Likewise, it was also shown that metallic fibres presented shear failures due to their ductility caused by the low aspect ratio, see Figure $6 \mathrm{~b}$.
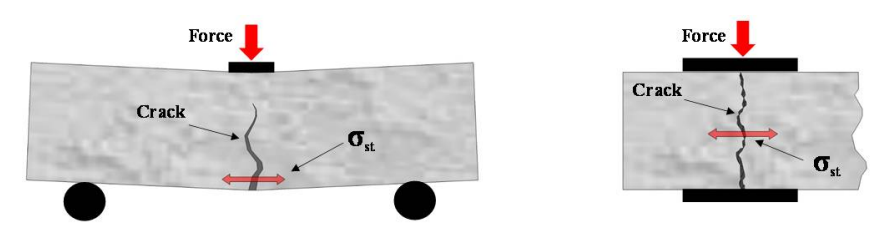

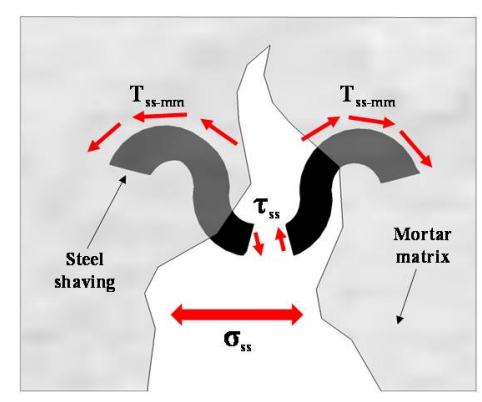

(a)

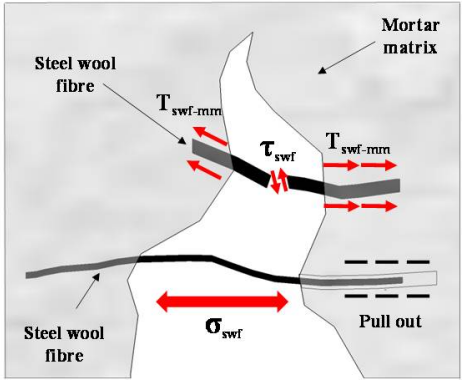

(b)

Figure 6. Schematic representation of the cracking produced during the strength tests: (a) flexural and (b) compressive tests for the cement mortar specimens with shavings and steel wool fibres, respectively. Symbol statement: $\sigma_{i}$ : Tensile strength (st: Specimen test; ss: Steel shaving; swf: Steel wool fibre); $\tau_{i}$ : Shear strength (ss: Steel shaving; swf: Steel wool fibre); and $T_{i-j}$ : Contact surface adherence load (ss: Steel shavings, swf: Steel wool fibre, mm: Matrix mortar).

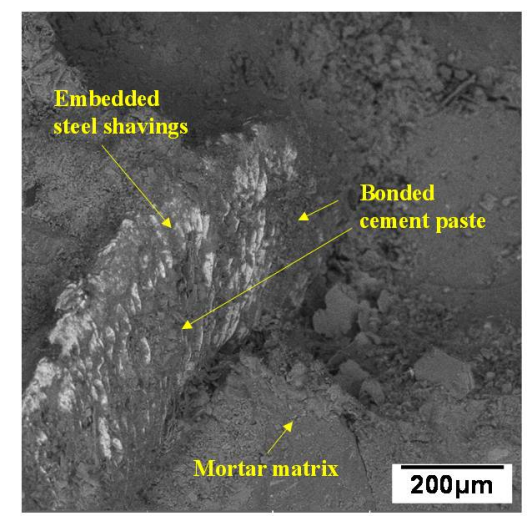

(a)

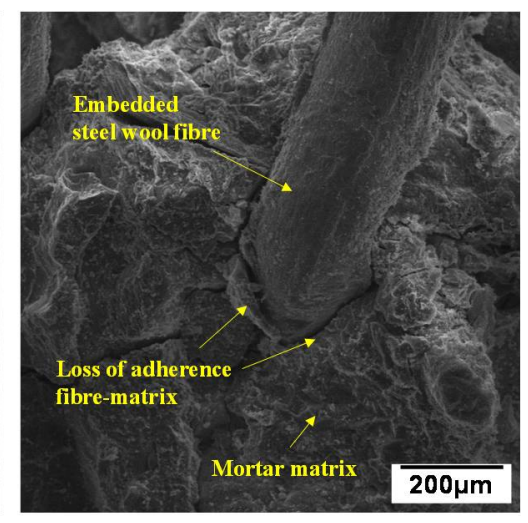

(b)

Figure 7. SEM images of the failure surfaces obtained by flexural tests on cement-mortar specimens with (a) shavings and (b) fibres.

Moreover, comparing the average values of flexural and compressive strength at the two curing times in Figure 5, a significant increase of the strength with the curing time was not observed, which could be due to the addition of the superplasticiser that contributed to homogenising the behaviour between the two curing ages evaluated. Likewise, analysing the error bars in Figure $5 \mathrm{a}, \mathrm{b}$, it can be observed that the type and amount of the metallic waste did not present a clear influence on the increase of the flexural and compressive strength of the cement mortars studied.

To demonstrate this hypothesis, Figure 8 shows the probability-probability (P-P) plots for all maximum force results obtained from flexural, Figure $8 \mathrm{a}$, and compressive tests, Figure $8 \mathrm{~b}$, adjusted to a normal distribution function. These data were represented regardless of the type and amount of metallic waste and the curing age. From the P-P plots, it can be observed that all data can be aligned to a straight line with a slope of 1:1, which proves that neither the type and amount of metallic waste, 
nor the curing age applied to the specimens, had a significant influence on the flexural and compressive strength of the mortars. This is a strong indication that such types of waste materials can be used without any worries about the mechanical performance of the cement-based composite.

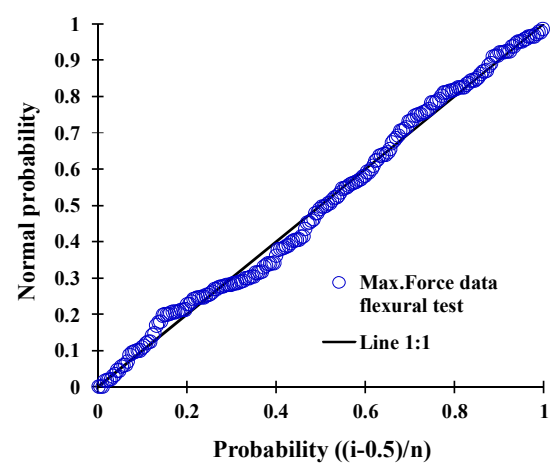

(a)

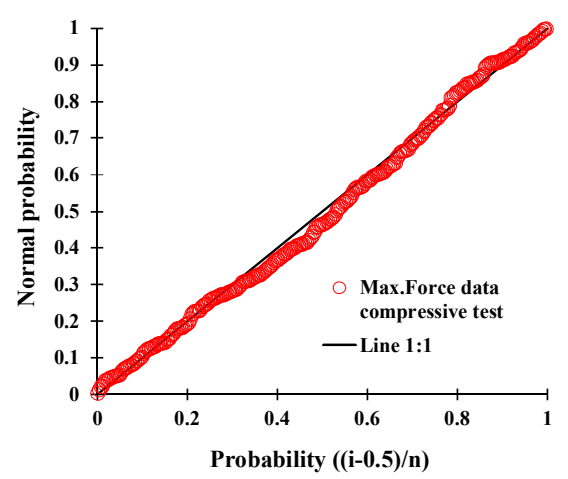

(b)

Figure 8. Normal probability-probability plots for the maximum force values registered under the (a) flexural and (b) compressive tests.

\subsection{Influence of Metallic Waste on the Elastic Modulus of the Test Specimens}

Figure 9 shows the average results of the static elastic modulus obtained from compressive tests $\left(E_{c}\right)$ and the dynamic elastic modulus obtained from ultrasonic tests $\left(E_{u}\right)$ of specimens with different amounts of fibres and shavings. From this Figure, it can be observed that: (i) the compressive elastic modulus proportionally increased with the increase of the amount of metallic waste added to the mortar, while (ii) the dynamic elastic modulus obtained from ultrasonic tests proportionally decreased with the increase of metallic waste.

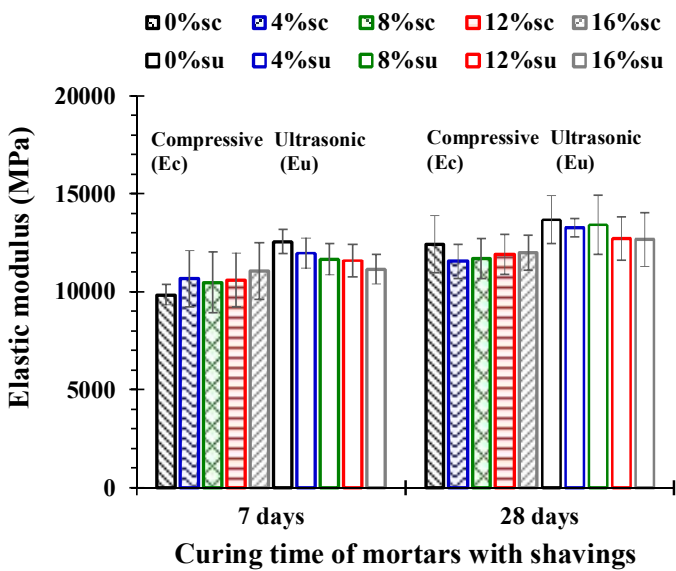

(a)

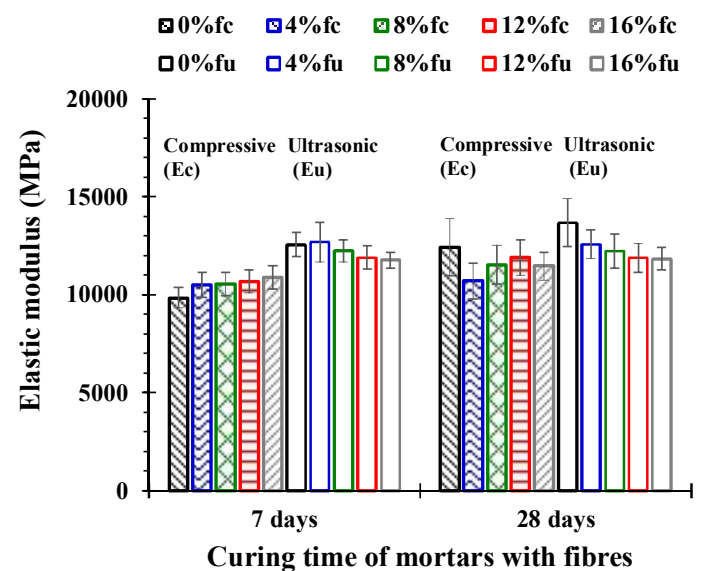

(b)

Figure 9. Average results of the elastic modulus obtained from compressive and ultrasonic tests of cement-mortar specimens reinforced with (a) steel shavings; and (b) steel wool fibres.

Additionally, comparing average values of the modulus obtained with the two different methods in Figure 9, it can be observed that the modulus measured by ultrasounds was higher than that measured by standard mechanical tests. This increase of magnitude in the modulus results can be associated with an increase in the test frequency, but it may also be due to the different testing methods [36]. Theoretically, the static compressive test considers the whole mechanical behaviour of materials, i.e., a stress-strain curve with a non-linear component. Nevertheless, the non-destructive 
method using ultrasonic tests evaluates the mechanical behaviour of materials just in the linear zone of the stress-strain curve, since it is a short time and high frequency test [32].

Furthermore, Figure 9 shows that regardless of the type of metallic waste and the curing time, the elastic modulus obtained by ultrasonic tests decreased with the increase of the amount of metallic waste added to the mortar specimens, reaching values in the order of magnitude of elastic modulus obtained from compressive tests. This can be due to the influence of metallic waste on the physical properties of the studied mortars. In order to prove that hypothesis, Figure 10 presents the average results of bulk density and porosity of all the evaluated specimens.

It can be observed that when the amount of metallic waste added to the mortar matrix increased, bulk density of the specimens decreased, consequently increasing their porosity, see Figure 10a,b, respectively. In this study, the obtained result was independent of the waste type and the curing age. Thus, specimens with higher contents of metallic waste (higher porosity) presented higher ultrasonic pulse times and consequently lower values of the dynamic modulus, see Figure 9.

Additionally, although previous works [32] proved that both elastic modulus types are physically related, we were not able to determine the static elastic modulus from the compressive test $\left(E_{c}\right)$, knowing the dynamic elastic modulus from ultrasonic tests $\left(E_{u}\right)$. With the aim of demonstrating this, Figure 11 shows the relationship between the elastic modulus obtained from compressive and ultrasonic tests, measured on the same test specimen for all the specimens tested.

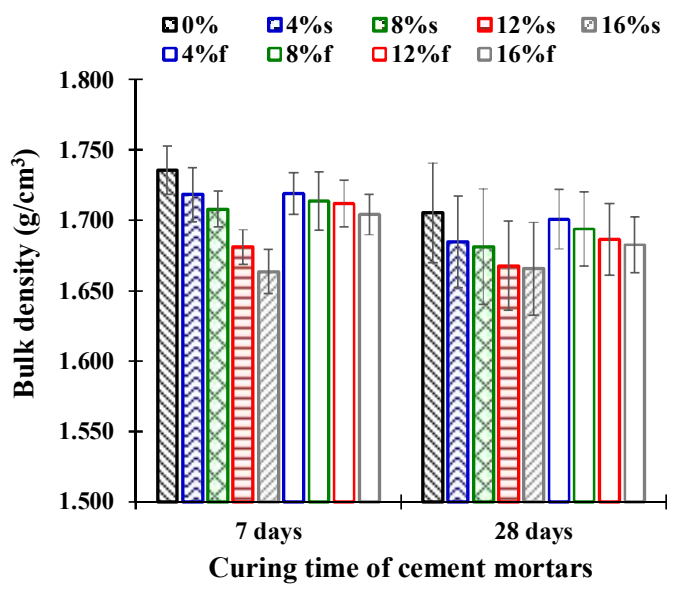

(a)

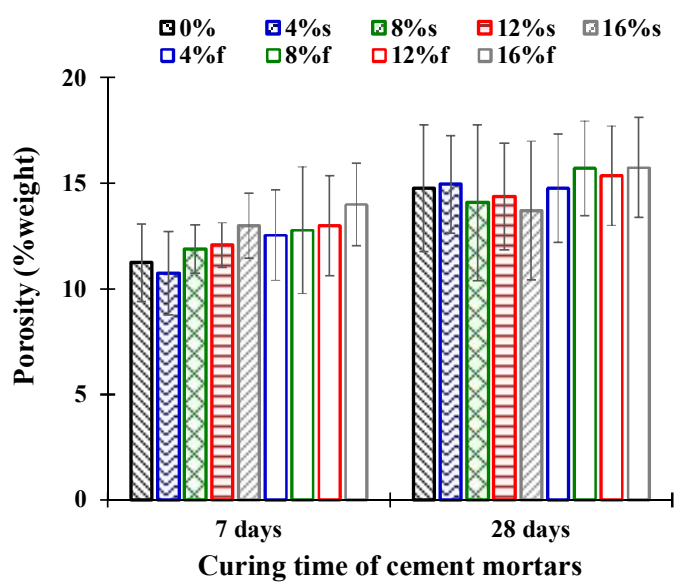

(b)

Figure 10. Average results of (a) bulk density and (b) porosity of the cement-mortar specimens with different waste content and curing times (s: shavings; f: steel wool fibres).

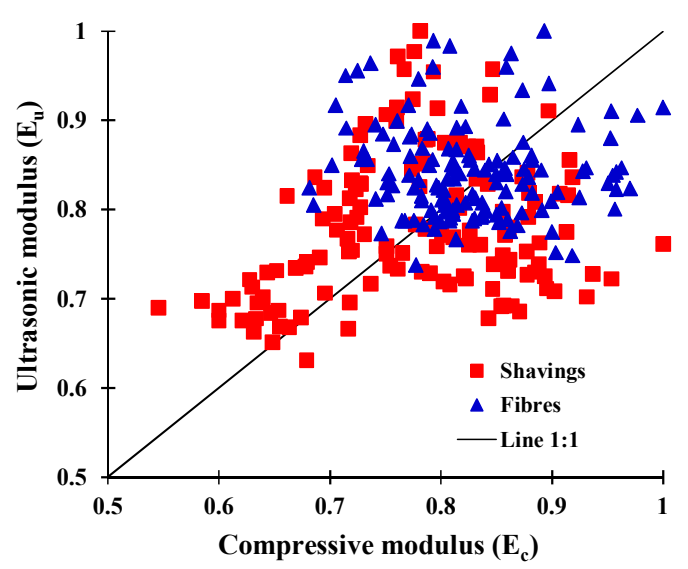

Figure 11. Relationship between the dimensionless compressive and ultrasonic elastic modulus. 
To facilitate their comparison, the moduli in Figure 11 have been normalised (0-1) dividing each value of modulus by the maximum value of each data series. By analysing Figure 11, it can be proven that there is no relationship between static and dynamic elastic modulus obtained from the mortar specimens reinforced with metallic fibres and shavings. This behaviour was due to the random distribution of metallic waste inside the test specimens [37], which can be interpreted as the scattering of the data in Figure 11.

Moreover, by analysing the error bars in Figure 9, it can be observed that the specimens with metallic waste did not present an increase in the elastic modulus with respect to the specimens without waste, in both elastic modulus types. With the purpose of evaluating the effect of the type and content of metallic waste on the elastic modulus measured by compressive and ultrasonic tests, the Modulus Influence Ratio $(M I R)$ was defined in this study. This Ratio was determined as the quotient between an i-th value of the elastic modulus of a specimen with metallic waste $\left(E_{i-\text { with waste }}\right)$ and the average value of the elastic modulus of the specimens without waste $\left(\bar{E}_{\text {without waste }}\right)$, evaluated for the same type of waste, curing age, and test method (compressive or ultrasonic test):

$$
M I R=\frac{E_{i-\text { with waste }}}{\bar{E}_{\text {without waste }}},
$$

Table 5 presents the average values of the Modulus Influence Ratios (MIRs) obtained for the compressive and ultrasonic elastic moduli, considering the different types of waste, contents, and curing ages. In this Table, it can be observed that the addition of metallic waste has greater influence on the compressive elastic modulus than on the ultrasonic modulus. The greatest influence was obtained in the case of the elastic modulus measured by compressive tests at a curing age of 7 days, reaching MIR values of 1.122 and 1.105 in specimens with $16 \%$ of shavings and fibres, respectively.

Table 5. Average results of Modulus Influence Ratios (MIRs) for the mortar specimens evaluated.

\begin{tabular}{ccccccccc}
\hline \multirow{2}{*}{$\begin{array}{c}\text { Metallic Waste } \\
\text { Content }\end{array}$} & \multicolumn{3}{c}{ Compressive Modulus $E \boldsymbol{c}$} & \multicolumn{3}{c}{ Ultrasonic Modulus $\boldsymbol{E u}$} \\
\cline { 2 - 9 } & \multicolumn{2}{c}{ 7 Days } & \multicolumn{2}{c}{ 28 Days } & \multicolumn{2}{c}{ 7 Days } & 28 Days \\
\cline { 2 - 9 } & Shavings & Fibres & Shavings & Fibres & Shavings & Fibres & Shavings & Fibres \\
\hline $4 \%$ & 1.083 & 1.068 & 0.930 & 0.861 & 0.953 & 1.010 & 0.971 & 0.920 \\
$8 \%$ & 1.064 & 1.071 & 0.941 & 0.928 & 0.928 & 0.975 & 0.981 & 0.894 \\
$12 \%$ & 1.077 & 1.085 & 0.958 & 0.957 & 0.923 & 0.948 & 0.930 & 0.869 \\
$16 \%$ & 1.122 & 1.105 & 0.965 & 0.922 & 0.889 & 0.937 & 0.926 & 0.865 \\
\hline
\end{tabular}

Likewise, it can be seen in Table 5 that MIRs obtained in the case of the ultrasonic elastic modulus decreased with the increase of the metallic waste content. This was due to the fact that the ultrasonic pulses are affected by the porosity of the specimens, as was previously discussed. Finally, analysing the MIR values of the elastic modulus obtained by compressive and ultrasonic tests, shown in Table 5, it can be observed that, in general, all data are close to 1 . This suggests that both the type and amount of waste and the curing time do not have a noticeable influence on the increase of the elastic modulus of reinforced mortars with respect to reference mortars without waste. To prove this, Figure 12 shows the probability-probability plots of all MIRs data, represented using a Weibull probability distribution function. The Weibull function has been chosen considering that the elastic modulus of mortars can be modelled as a mechanical process of fracture [10], because the fracture produced by compressive efforts is caused due to the multiple cracks that are produced during the mechanical load cycle. These data were plotted regardless of the amount of metallic waste and the curing time. In this Figure, it was observed that all the data, for both the compressive and ultrasonic modulus, can be aligned to a straight line with a slope 1:1, which indicates that neither the type and amount of waste, nor the curing time, presented a significant influence on the elastic modulus of mortars measured using the two different test methods: destructive $\left(E_{c}\right)$ and non-destructive $\left(E_{u}\right)$. 


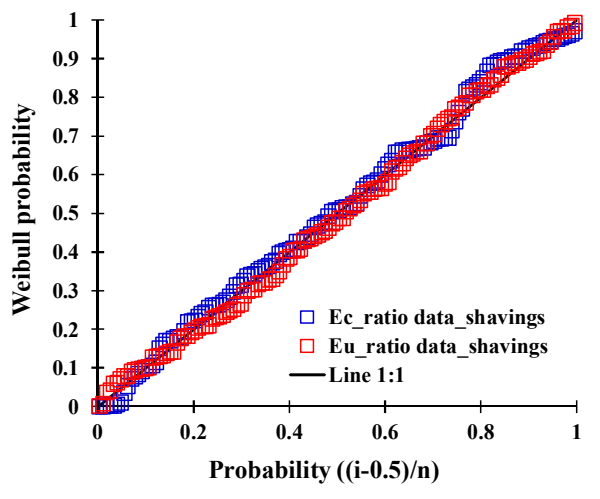

(a)

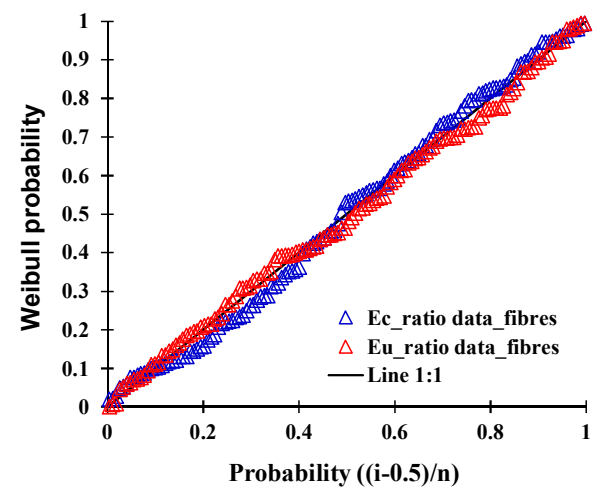

(b)

Figure 12. Weibull probability-probability plots of the Modulus Influence Ratios (MIRs) data, for all specimens reinforced with (a) shavings and (b) fibres.

\section{Conclusions}

This paper has explained the influence of the type and amount of two different types of metallic waste on the physical and mechanical properties of cement-based mortars. The main conclusions in this article are summarised as follows:

- Regarding the mechanical performance of mortar specimens, it was concluded that the addition of metallic waste produced slight variations on their flexural and compressive strength. In addition, mechanical resistance of mortar specimens with metallic waste proportionally increased with the increase of the waste content.

- Additionally, it was found that specimens with shavings presented, on average, higher values of their mechanical properties than did specimens with fibres. This was attributed to the surface aspect of metallic waste, since shavings have a rough surface that facilitated the adherence between them and the mortar matrix, thus avoiding slipping on the shavings' edges, while fibres presented a smooth surface, which was more susceptible to failure by pull-out slipping.

- Furthermore, the results showed that the compressive elastic modulus increased with the amount of metallic waste added to the mortar, while in contrast, the dynamic elastic modulus obtained from ultrasonic tests decreased with the increase of metallic waste. This was associated with the increase on the mortar porosity due to the addition of metallic waste, which resulted in specimens with higher contents of metallic particles presenting higher ultrasonic pulse times and consequently lower values of dynamic moduli.

- Moreover, it was found that the elastic modulus measured by ultrasonic tests was on average higher than that measured by compressive tests. Besides, due to the random distribution of metallic waste inside the test specimens, there was no relationship between the static and dynamic elastic moduli, in contrast with conclusions obtained in previous works.

- Finally, based on a probability analysis of the obtained results, it was concluded that neither the type and amount of metallic waste, nor the curing time applied to the mortar specimens produced a significant variation on either the mechanical strength (flexural and compressive) or the elastic modulus of mortars measured by destructive and non-destructive methods.

Considering that the metallic waste addition did not compromise the mechanical performance of the cement-based mortars, a continuation of this study, an exploratory study to evaluate the cracking damage self-monitoring properties of cement mortars by measuring the variation of their electrical resistance, is currently being developed.

Author Contributions: J.N.-C. was responsible for all the research presented in this paper. He conceived the idea and designed the experiments, and his work was focused on the data interpretation and manuscript writing. 
A.C. and I.G.-T. performed the experimental tests and were responsible of data collection and analysis. M.C. was responsible for the development of the experimental program. A.K. provided technical advice, and revised and improved the manuscript.

Acknowledgments: The authors would like to acknowledge the help provided by Olga Iturra from the Laboratory of Civil Engineering from the University Andres Bello. In addition, the authors want to thank José Luis Concha from LabMAT for the technical support given and the company Sika S.A. Chile for the provision of the additive. Finally, the authors wish to express their gratitude to Roque Borinaga-Treviño from the University of the Basque Country (UPV/EHU) for his help at the beginning of the experimental programme.

Conflicts of Interest: The authors declare no conflict of interest. The founding sponsors had no role in the design of the study; in the collection, analyses, or interpretation of data; in the writing of the manuscript, and in the decision to publish the results.

\section{References}

1. Liu, Z.; Hansen, W. Pore damage in cementitious binders caused by deicer salt frost exposure. Constr. Build. Mater. 2015, 98, 204-216. [CrossRef]

2. Zhutovsky, S.; Hooton, R.D. Experimental study on physical sulfate salt attack. Mater. Struct. 2017, $50,54$. [CrossRef]

3. Koenig, A.; Dehn, F. Main considerations for the determination and evaluation of the acid resistance of cementitious materials. Mater. Struct. 2016, 49, 1693-1703. [CrossRef]

4. Çavdar, A. Investigation of freeze-thaw effects on mechanical properties of fiber reinforced cement mortars. Compos. Part B Eng. 2014, 58, 463-472. [CrossRef]

5. Bentur, A.; Mindess, S. Fiber Reinforced Cementitious Composites, 2nd ed.; Taylor \& Francis: Abingdon, UK; Oxon, UK, 2007.

6. Banthia, N.; Dubeau, S. Carbon and steel microfiber-reinforced cement-based composites for thin repairs. J. Mater. Civ. Eng. 1994, 6, 88-99. [CrossRef]

7. Brandt, A.M. Fibre reinforced cement-based (FRC) composites after over 40 years of development in building and civil engineering. Compos. Struct. 2008, 86, 3-9. [CrossRef]

8. Quadir, U.M.T.; Islam, K.; Billah, A.M.; Alam, M.S. Mechanical and durability properties of concrete using recycled granulated steel. Constr. Build. Mater. 2016, 123, 174-183. [CrossRef]

9. Pacheco-Torgal, F.; Jalali, S. Cementitious building materials reinforced with vegetable fibres: A review. Constr. Build. Mater. 2011, 25, 575-581. [CrossRef]

10. Norambuena-Contreras, J.; Thomas, C.; Borinaga-Treviño, R.; Lombillo, I. Influence of recycled carbon powder waste addition on the physical and mechanical properties of cement pastes. Mater. Struct. 2016, 49, 5147-5159. [CrossRef]

11. Nishiwaki, T.; Koda, M.; Yamada, M.; Mihashi, H.; Kikuta, T. Experimental study on self-healing capability of FRCC using different types of synthetic fibers. J. Adv. Concr. Technol. 2012, 10, 195-206. [CrossRef]

12. Martinelli, E.; Caggiano, A.; Xargay, H. An experimental study on the post-cracking behaviour of Hybrid Industrial/Recycled Steel Fibre-Reinforced Concrete. Constr. Build. Mater. 2015, 94, 290-298. [CrossRef]

13. Sengul, O. Mechanical behavior of concretes containing waste steel fibers recovered from scrap tires. Constr. Build. Mater. 2016, 122, 649-658. [CrossRef]

14. Graeff, A.G.; Pilakoutas, K.; Neocleous, K.; Peres, M.V.N.N. Fatigue resistance and cracking mechanism of concrete pavements reinforced with recycled steel fibres recovered from post-consumer tyres. Eng. Struct. 2012, 45, 385-395. [CrossRef]

15. Holschemacher, K.; Mueller, T.; Ribakov, Y. Effect of steel fibres on mechanical properties of high-strength concrete. Mater. Des. 2010, 31, 2604-2615. [CrossRef]

16. Wang, H.T.; Wang, L.C. Experimental study on static and dynamic mechanical properties of steel fiber reinforced lightweight aggregate concrete. Constr. Build. Mater. 2013, 38, 1146-1151. [CrossRef]

17. Wu, Z.; Shi, C.; He, W.; Wu, L. Effects of steel fiber content and shape on mechanical properties of ultra high performance concrete. Constr. Build. Mater. 2016, 103, 8-14. [CrossRef]

18. Norambuena-Contreras, J.; Quilodran, J.; Gonzalez-Torre, I.; Chávez, M.; Borinaga-Treviño, R. Electrical and thermal characterisation of cement-based mortars containing recycled metallic waste. J. Clean. Prod. 2018, 190, 737-751. [CrossRef] 
19. Lee, S.F.; Jacobsen, S. Study of interfacial microstructure, fracture energy, compressive energy and debonding load of steel fiber-reinforced mortar. Mater. Struct. 2011, 44, 1451-1465. [CrossRef]

20. Kim, D.J.; Kang, S.H.; Ahn, T.H. Mechanical Characterization of high-performance steel-fiber reinforced cement composites with self-healing effect. Materials 2014, 7, 508-526. [CrossRef] [PubMed]

21. Nguyen, D.L.; Song, J.; Manathamsombat, C.; Kim, D.J. Comparative electromechanical damage-sensing behaviors of six strain-hardening steel fiber-reinforced cementitious composites under direct tension. Compos. Part B Eng. 2015, 69, 159-168. [CrossRef]

22. Erdem, S.; Hanbay, S.; Blankson, M.A. Self-sensing damage assessment and image-based surface crack quantification of carbon nanofibre reinforced concrete. Constr. Build. Mater. 2017, 134, 520-529. [CrossRef]

23. Wang, H.; Gao, X.; Wang, R. The influence of rheological parameters of cement paste on the dispersion of carbon nanofibers and self-sensing performance. Constr. Build. Mater. 2017, 134, 673-683. [CrossRef]

24. Al-Dahawi, A.; Yıldırım, G.; Öztürk, O.; Şahmaran, M. Assessment of self-sensing capability of Engineered Cementitious Composites within the elastic and plastic ranges of cyclic flexural loading. Constr. Build. Mater. 2017, 145, 1-10. [CrossRef]

25. Lataste, J.F.; Behloul, M.; Breysse, D. Characterisation of fibres distribution in a steel fibre reinforced concrete with electrical resistivity measurements. NDT E Int. 2008, 41, 638-647. [CrossRef]

26. ASTM C595/C595M-16. Standard Specification for Blended Hydraulic Cements; ASTM International: West Conshohocken, PA, USA, 2016.

27. EN 196-3:2005+A1:2009. Methods of Testing Cement-Part 3: Determination of Setting Times and Soundness; CEN European Committee for Standardization: Brussels, Belgium, 2009.

28. ASTM C642-13. Standard Test Method for Density, Absorption, and Voids in Hardened Concrete; ASTM International: West Conshohocken, PA, USA, 2013.

29. ASTM C348-14. Standard Test Method for Flexural Strength of Hydraulic-Cement Mortars; ASTM International: West Conshohocken, PA, USA, 2014.

30. ASTM C349-14. Standard Test Method for Compressive Strength of Hydraulic-Cement Mortars (Using Portions of Prisms Broken in Flexure); ASTM International: West Conshohocken, PA, USA, 2014.

31. ASTM C597-16. Standard Test Method for Pulse Velocity through Concrete; ASTM International: West Conshohocken, PA, USA, 2016.

32. Valentini, L.; Parisatto, M.; Russo, V.; Ferrari, G.; Bullard, J.W.; Angel, R.J.; Dalconi, M.C.; Artioli, G. Simulation of the hydration kinetics and elastic moduli of cement mortars by microstructural modelling. Cem. Concr. Compos. 2014, 52, 54-63. [CrossRef]

33. Norambuena-Contreras, J.; Gutierrez Aguilar, V.; González-Torre, I. Physical and mechanical behaviour of a fibre-reinforced membrane with self-healing purposes via microwave heating. Constr. Build. Mater. 2015, 94, 45-56. [CrossRef]

34. Norambuena-Contreras, J.; Serpell, R.; Valdés, G.; Gonzalez, A.; Schlangen, E. Effect of fibres addition on the physical and mechanical properties of asphalt mixtures with crack-healing purposes by microwave radiation. Constr. Build. Mater. 2016, 127, 369-382. [CrossRef]

35. García, A.; Norambuena-Contreras, J.; Partl, M.N.; Schuetz, P. Uniformity and mechanical properties of dense asphalt concrete with steel wool fibers. Constr. Build. Mater. 2013, 43, 107-117. [CrossRef]

36. Norambuena-Contreras, J.; Castro-Fresno, D.; Vega-Zamanillo, A.; Celaya, M.; Lombillo-Vozmediano, I. Dynamic modulus of asphalt mixture by ultrasonic direct test. NDT E Int. 2010, 43, 629-634. [CrossRef]

37. Sevkat, E.; Li, J.; Liaw, B.; Delale, F. A statistical model of electrical resistance of carbon fiber reinforced composites under tensile loading. Compos. Sci. Technol. 2008, 68, 2214-2219. [CrossRef]

(C) 2018 by the authors. Licensee MDPI, Basel, Switzerland. This article is an open access article distributed under the terms and conditions of the Creative Commons Attribution (CC BY) license (http://creativecommons.org/licenses/by/4.0/). 